\title{
DIE BONTBOK
}

\author{
deur \\ N. J. VAN DER MERWE, \\ Skakel-/Navorsingsbeampte, Pretoria.
}

Die oorspronklike verspreidingsgebied van die bontbok, Damaliscus dorcas dorcas (Pallas) [Meester, e.a. (9)], 'n gedeelte wat vandag bekend staan as die Suidwestelike Distrikte, was voor die koms van die Blanke deur die Hessekwa- en Gourikwa-hottentotte bewoon [Rothman (11), Thomlinson (14)].

Die kus, en veral Mosselbaaigebied, was reeds aan die seevaarders, Portugese, Hollanders en Engelse, bekend, maar die binneland nie, totdat Kommandeur Quaelberg in 1667 'n ekspedisie onder Korporaal H. Cruse oor die Hottentots-Hollandberge gestuur het om beeste en skape daar te gaan ruil.

Hierdie ekspedisie en die een later in 1676 onder Lourens Visser, het albei van die groot skaal waarop die Hottentotte met vee geboer het gerapporteer [Rothman (11), Thomlinson (14)], maar niks van die ve!'dlewe vertel nie.

Die Hottentotte was veeboere en vér te lui om te jag. Hulle het hoogstens hulle veetroppe teen roofdiere soos leeus, luiperds, strandjutte, jakkalse en rooikatte beskerm, maar veral ook teen die strooptogte van die Boesmans.

Die eerste blanke koloniste het ongeveer aan die begin van die agtiende eeu dié gebied, wat algou as Overberg bekend gestaan het, binnegetrek en begin om met vee sowel as graan, wingerd, vrugte en groente te boer. Dit was dus hulle wat dadelik met die wilde diere gebots het. Boesmans het ook aanvanklik groot las gegee, maar die Hottentotte se getalle was na 1713 se pokke-epidemie so vitgedun dat hulle as stamme verdwyn het en die oorblywendes hulle as plaasvolk aan die boere verhuur het.

Dat die boere wel deeglik ook van die veldlewe kennis geneem het blyk vit sulke plaasname soos Bontebokskloof, Renosterfontein, Hartebeesfontein, en so meer. Dit kan ook aanvaar word dat daar heelwat gejag was om nie onnodig onder hulle vee te slag nie, want wild was toe nog volop.

Die wonderlike plant- en dierelewe van die Kaap het ook baie gou in Europa bekend geword en teen die middel van die 18de eeu was daar nagenoeg 'n stormloop van wetenskaplikes en jagters wat hier versamelwerk kom doen en kom jag het. So was onder die eerstes om die huidige 


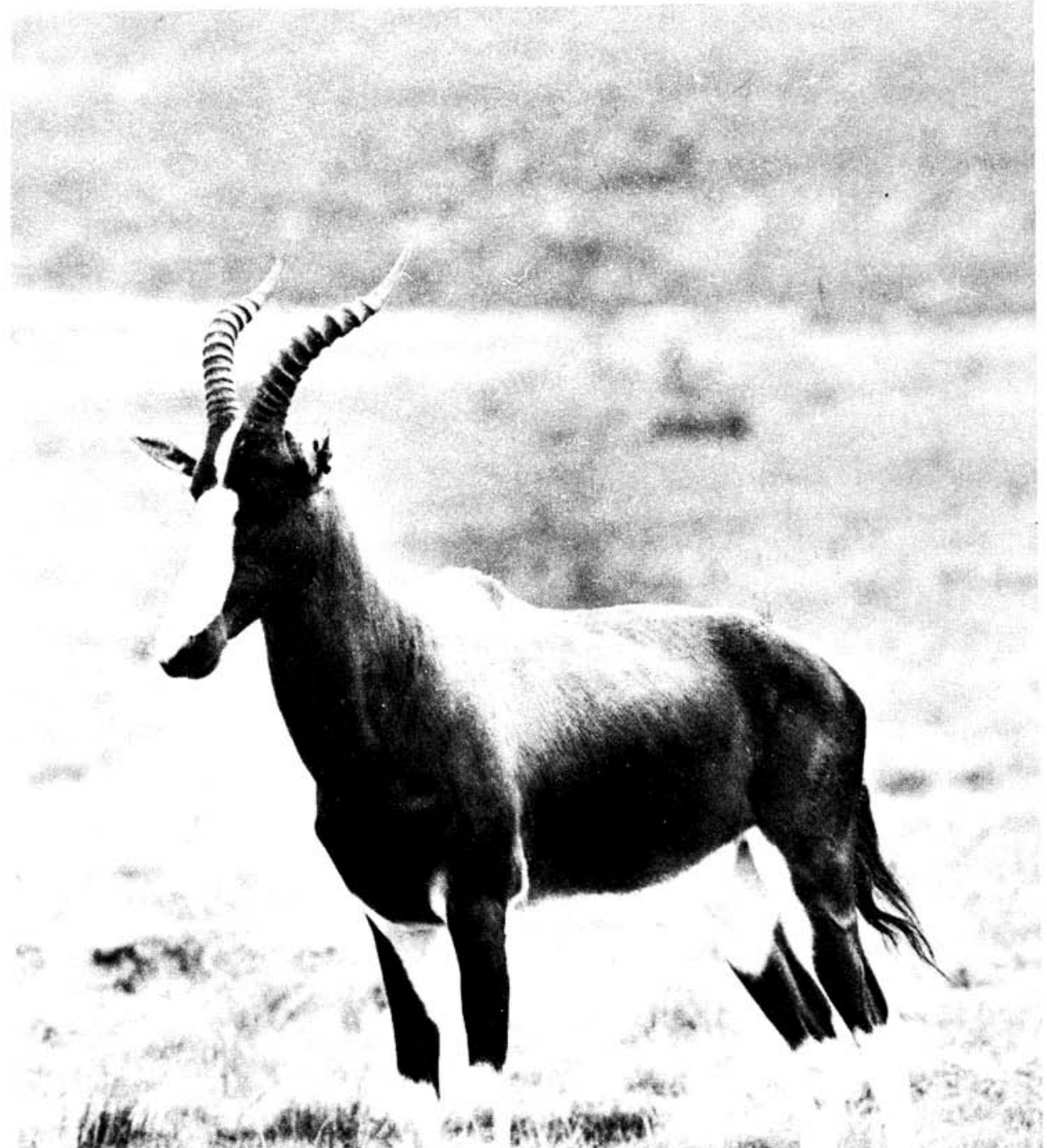

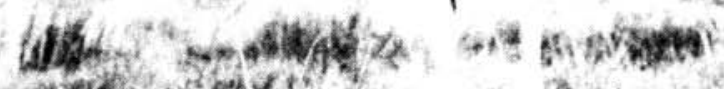

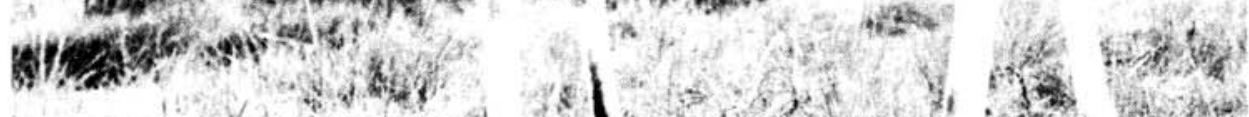
(3)

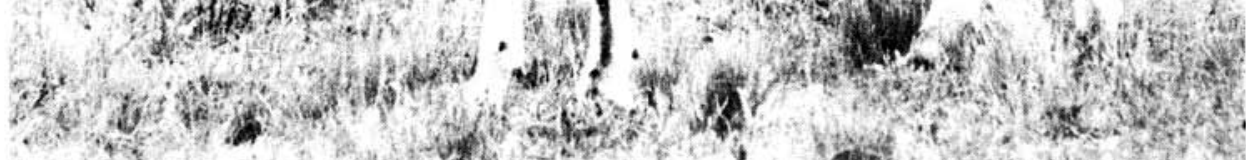

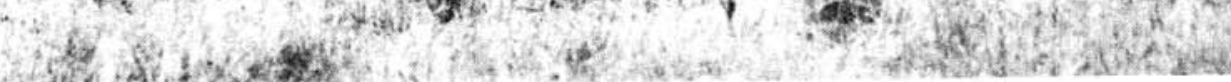

Bontbok.

Foto: A. Zaayman. 
Swellendam te bereik die Engeisman Francis Masson en die Sweed Carl Thunberg, wat in die jare 1772 tot 1775 by geleentheid daar vertoef het. Hierop het gevolg: Sparrman (1776), Patterson (1777), le Vaillant (1781), Lichtenstein (1803) en Burchell (1815).

Thomlinson (14) gee ' $n$ lys van diere wat in die verlede in Swellendam se omgewing aangeteken was, dit sluit in: bontbokke, bloubokke, bosbokke, ribbokke, klipsprigers, duikers, steenbokke, grysbokke, koedoes, buffels, elande, olifante, seekoeie, renosters, leeus, luiperds, wolwe (vermoedelik strandjutte en gevlekte hiënas), jakkalse, wildekatte en wildehonde.

Die bontbok is in 1.766 vir die eerste keer deur 'n Russiese wetenskaplike met name Pallas beskryf. Roberts (10), Harper (3) en Sclater (12) aanvaar, waarskynlik op gesag van Masson (8), dat hy dié eksemplaar van Kafferskuilsrivier by Riversdal gekry het.

Oor die juiste oorspronklike verspreidingsgebied is daar onsekerheid. Roberts (10) sê dat dit van Knysna af tot Caledon gestrek het, maar van ons kennis van die huidige behoeftes van die bontbok, wil dit voorkom of dit slegs van Mosselbaai tot Caledon was. Labuschagne (5) na raadpleging van die beskikbare bronne stel die verspreidingsgebied as ,in die streek tussen Botrivier in die weste en Gouritzrivier in die ooste, die Langebergreeks in die noorde en die see in die suide".

Hoewel Le Vaillant (7) in 1781 opteken dat hy tussen Botrivier en Caledon groot troppe bontbokke, hartbeeste, ander boksoorte, kwaggas en volstruise aangetref het en daar dus met veiligheid aanvaar kan word dat ook die bontbokke volop was, was die prentjie aan die begin van die 19de eeu reeds heelwat anders. Harris (4) noem dat tydens sy besoek gedurende 1836, die onwettige jag op die bontbok met 'n boete van R75.00 strafbaar was. Dit was dus reeds op daardie stadium noodsaaklik om hulle streng te beskerm.

Wat ook al die invloed van faktore soos jag, veesiektes, ens. op die bontbok mag gewees het, die grootste enkele faktor wat waarskynlik sy getalle moes beïnvloed het, was die ontwikkeling van plase. Groter en groter dele van sy weigebiede is deur landerye, boorde en wingerde ingeneem en buitekant moes hy met skaap en bees om weiding wedywer. Hierdie druk het meer en meer toegeneem totdat hy later na die suur strandveld moes uitwyk, en hy sal heelwaarskynlik soos die bloubok in die stryd ondergegaan het en verdwyn het as daar nie viteindelik na hulle omgesien is deur boerefamilies soos die Albertyns, Van der Byls, Van Breda's en Uyse nie. Best (2) noem dat die bontbok reeds in 1864 op die plase Nachtwacht en Zeekoe Vlei skuiling gevind het.

Die feit dat hierdie plase, en nog een, bekend as Bonte Boks Vallei, wes van Bredasdorp amper op die kus geleë is, wys net hoever hierdie boksoort reeds in daardie jare vit sy oorspronklike habitat verdryff was. Harris (4) meld selfs bontbokke by Zoetendalsvlei naby Kaap L'Agulhas.

Ons weet baie min van die lot van die bontbok sedert 1864, maar dit weet ons wel dat toe die Nasionale Parkeraad gedurende Junie 1930 die 
plaas Quarrie Bos, ongeveer 844 morg groot, in die hande gekry het, was slegs 17 bontbokke in die omgewing beskikbaar om in die nuwe Nasionale Park, wat gedurende 1931 geproklameer is, in te ja en hulle is teen R40 stuk van die boere aangekoop.

Aanvanklik het dit met hierdie kern goed gegaan en hulle het in getalle toegeneem, maar dat sake later nie na wense was nie, blyk vit die feit dat twee Raadslede (mnr. W. A. Campbell en brig. C. H. Blaine) die Park gedurende 1948 op die Raad se versoek besoek het en daarop aanbeveel dat tenminste 100 acre skoongemaak moes word van renosterbos en dat dit omgeploeg en met gras beplant moes word. Die Raad het ook 72 laat vang en aan belanghebbendes verkoop en geskenk.

Gedurende 1953 het die Raad se bioloog en assistent-bioloog die Park besoek. Hulle rapporteer dat daar volgens die veearts (dr. T. Smuts) 'n tekort aan minerale voedselsoorte veral spoorelemente is en dat dit saam met parasietbesmetting verantwoordelik was vir die swak toestand van die bontbokke in die Park. Hulle rapporteer 'n totaal van 115 bokke 130 ramme, 62 ooie en 23 lammers) en beveel aan dat die ramme verminder word tot 10 en die ooie tot 44, deur vit te vang en aan boere te voorsien, sowel as twee aan die Nasionale Dieretuin, Pretoria, te skenk en ses ramme vir eie navorsing beskikbaar te stel. Verder stel hulle voor dat die vitbreiding van aangeplante weidings aandag moet geniet en dat dit onderhewig aan proewe moet geskied en hulle beveel ook aan dat die spoorelementtekorte deur die gebruik van 'n geskikte kunsmismengsel aangevul moet word.

Gedurende Maart 1954 besluit die Raad om die moontlikheid om weiding vir bontbokke op die stuk kroongrond, bekend as De Mond, aan die Bredasdorpse kus en op die militêre vliegveld naby die Park te bekom, te ondersoek en die Skakelbeampte (R. J. Labuschagne) word met hierdie taak belas. Raadslid W. H. Faurie is ook gevra om dié saak met die betrokke Ministers op te neem.

Dit kan hier gerapporteer word dat die nodige verlof deur die twee betrokke staatsdepartemente (Verdediging en Bosbou) toegestaan is maar dat die onderhandelings met die boere in die omgewing, om deurtog te verkry, afgespring het en dat presies 3 jaar later die Raad, na 'n bespreking van ' $n$ verslag van die Skakelbeampte (R. J. Labuschagne) besluit het om die Minister van Lande om verlof te nader om vir ' $n$ heeltemal nuwe park in die Caledon- of Swellendamdistrik te begin soek. Sy Ed. P. O. Saver, die betrokke Minister, het dan ook vir geen oomblik getwyfel nie en op 7 Junie 1957 word so 'n opdrag aan die Raad onderteken. Hierin word die distrikte Darling en Hopefield in die Malmesbury-afdeling ook genoem as moontlike gebiede om te ondersoek. Hierdie taak is weer eens aan die Skakelbeampte opgedra, ' $n$ taak wat hy met die grootste ywer en nougesetheid aangepak het.

In hierdie bogenoemde vorderingsverslag van die Skakelbeampte [Labuschagne (5)] wat aan die Raad op 8 Maart 1957 voorgelê is, noem hy dat die bontbok in die park gladnie na wense vorder nie. Daar is ' $\mathrm{n}$ groot 
afname in hulle getal en hy waarsku dat indien lamkruis las gevolg van gebrek aan spoorelemete) en die bosluise nie daadwerklik bekamp word nie, die voortbestaan van die bontbok bedreig word. Die vorige teeltyd het 40 lammers gelewer maar 18 het as gevolg van bosluisaanvalle gevrek, terwyl lamkruis die groot bokke swaar getref het.

Labuschagne (5) wys ook daarop dat alle Nasionale Parke onder die Raad se beheer die tipiese omgewing verteenwoordig maar dat hierdie Park nie aan die behoeftes voldoen nie en hy sluit af met die spesifieke voorstel dat die tyd gekom het dat die bontbok na 'n geskikter oord geneem moes word.

Die daaropvolgende verslag van die Skakelbeampte [Labuschagne (6)] moet eenvoudig beskou word as die keerpunt in die bedreigde bestaan van die bontbok. Hierin wys hy daarop dat "alle pogings aangewend is om toestande (in die ou Park) te verbeter. Teen geweldige koste is die renosterbos op 250 morg afgesny en die grond behandel met kunsmis, kalk en gekorrelde kopersulfaat. Die grasherwinning op hierdie gebied was eenvoudig pragtig. Sewentig morg is onder aangeplante weiding van ondergrondse klawer, lusern, roggras ens. Al die bokke konsentreer op hierdie stuk grond. Dit is egter geen onbekende feit nie, dat aangeplante weiding gunstige toestande skep vir sekere (inwendigel parasiete. Verlede jaar is 49 bokke as gevolg van parasietbesmetting dood, volgens dr. T. Smuts, Veearts te Caledon".

Hy het ook die lot van die verskillende bontbokke wat aan boere voor 1953 verskaf was angespeur en bevind dat behalwe dié wat aan A. W. M. Bowker (Thornkloof, Grahamstad) voorsien is, "geen voordeel gehad het nie".

Labuschagne (6) kom tot die gevolgtrekking dat "die bontbok 'n besliste vereiste stel aan natuurlike grasse", m.a.w. dat dit 'n selektiewe vreter is en dit hou waarskynlik die rede in waarom die bontbok in die Bredasdorpse Park in so 'n swak toestand verkeer het.

By gebrek aan behoorlike opnames kan daar alleen vermoed word dat toe die oorspronklike bontbokkudde in 1931 in die Park ingejaag was, daar gunstige weidingstoestande was en as gevolg daarvan en die beskerming, hulle in getalle vinnig aangewas het, tot so ' $n$ mate dat die Raad oorbeweiding wou verhoed deur van hulle te laat uitvang en aan boere beskikbaar te stel.

Hoewel daar 'n aantal ribbokke en enkele duikers, steenbokke en grysbokkies was, it dit ook duidelik dat hulle voedingsbehoeftes óf met dié van die bontbok ooreengestem het, óf hulle getalle was te klein om enige indruk op die ander gewasse te maak en dat die onvreetbare soorte die reeds oorbeweide nuttige soorte later eenvoudig verdring het.

Uit verslae aan die Raad is dit ook duidelik dat die kunsmatige aanplanting van weidings tog weer 'n gunstige gevolg gehad het, maar dat dit 
tydelik van aard was en dat die parasietbesmetting, wat deur aangeplante weidings begunstig word, sy invloed sterk laat geld het.

Gebrekkige weiding, parasietbesmetting en die ongunstige winterklimaat Iveral wanneer groot gedeeltes van hierdie park se vleie onder water gestaan het) het die posisie dus eenvoudig onuithoubaar gemaak.

Labuschagne (6) rapporteer dat hy ,in samewerking met twee Landbouvoorligtingsbeamptes van die winterreënvalstreek gedurende Oktober 1957 die gebied van Mosselbaai tot by Bettiesbaai, tussen die berge en die see, gefynkam" het. Die distrikte van Riversdal, Heidelberg, Swellendam, Caledon, Montagu en Worcester het sy aandag geniet, maar viteindelik het hy net een plek aan te beveel, nl. die dorpsmeent van Swellendam. Hy bevind, na alles sorgvuldig oorweeg is, dat dié grond geskik is vanweë sy ligging, grootte (met die moontlikheid van latere vitbreiding), grondtoestand, klimaat en toeganklikheid, maar veral weens sy plantegroei en weidingstoestande. Hy sluit sy verslag (6) af met die woorde: "Hierdie park kan ontwikkel in iets moois en groots. 'n Park met nasionale status".

Op 10 Desember 1957 aanvaar die Raad hierdie verslag, maar besluit om gedurende Maart 1958 die ou Park te besoek voordat magtiging verleen word om daadwerklik oor te gaan om te onderhandel om 'n nuwe Park op die dorpsmeent van Swellendam te kry. Hierdie besoek is dan ook afgelê deur drie Raadslede, nl. Hulle Edeles F. H. Odendaal en J. N. Malan, en mnr. C. T. J. Hannah, L.V. Hulle het ook terselfdertyd ' $n$ onderhoud met die Stadsraad van Swellendam gevoer. Onderhandelings vir meer grond is later ook met mnre. M. G. Lourens, P. G. Lourens en Paulsen deur die Skakelbeampte (R. J. Labuschagne) en die Raad se Sekretaris (P. Heslinga) aangeknoop.

Al hierdie onderhandelings het gelei tot die aanvaarding op 9 Mei 1958 deur die Raad van 'n voorstel dat vertoë gerig word aan die Minister van Lande om die volgende gronde by Swellendam aan te koop vir die doel om die bontbokke daarheen te verskuif:

(1) 1,400 morge van Swellendam se dorpsmeent,

(2) 1,200 morg van mnr. M. G. Lourens,

(3) 100 morg van mnr. P. G. Lourens, en

(4) ' $n$ heel klein gedeelte aan die suidekant van die Breërivier wat aan mnr. Paul Dunn behoort.

Die Staat het viteindelik 1,607.5 morg van die Swellendamse dorpsmeent gekoop en skenkings van grond deur mnre. Piet Lourens en Paul Dunn het die oppervlakte op 1,706 morg te staan gebring. Hierdie gebied is op 24 Maart 1961 tot park geproklameer, maar toe was die bontbokke al meer as ' $\mathrm{n}$ jaar daar.

In die ou park was daar teen die einde van 1959 slegs 95 bontbokke oor en baie aandag is gegee aan verskillende vangmetodes en proewe is gedoen met verdowingsmiddels [Barnard e.a. (1)] in die drinkwater ens., 
maar viteindelik is besluit om die trop in ' $n$ drukgang te vang en so is 84 bokke aan die einde van Maart, begin April, 1960 gevang en onder die invloed van kalmeermiddels na die nuwe park verskuif. Ongelukkig het net 61 in die proses oorleef, maar dit was nagenoeg al die ou diere wat reeds so deur parasiet-besmetting en ouderdom verswak was dat die spanning en uitputting vir hulle te kwaai was [Barnard e.a. (1)].

Die paar jong rooihartbeeskalwers wat van die Kalahari-gemsbokpark afkomstig was, is saam oorgebring en hiermee het die groot taak om die dieregemeenskap soos dit in die verlede was, weer te herstel begin.

In die park self was daar steenbokkies, duikers en heelwat vaalribbokke, maar die Raad het baie gou springbokke, elande en volstruise ingevoer. Die eerste bontboklam is op 30 Augustus 1962 in die park gebore en toe Sy Ed. P. Saver, destyds Minister van Lande die park op 10 Oktober 1962 vir die publiek oopgestel het, was die getal bontbokke reeds 84 .

Sedertdien is Kaapse buffels in die Addo-olifantpark gevang en ingevoer. Vyf rietbokke, afkomstig van die Transvaalse Bosveld, het ook hier 'n tuiste gevind soos ook bosbokke uit Swellendamomgewing.

Op 16 Oktober 1963 het die Adjunk-direkteur begin met 'n korrespondensie om die Staat te beweeg om verdere grondaankopings te doen van mnre. M. G. Lourens en A. A. P. Odendaal. Dit was geslaagd en gedurende Desember 1965 kry die Raad kennis dat twee gedeeltes, een van 1,142 morg 19,584 vk. voet en ' $n$ tweede van 433.7231 morg deur die Staat aangekoop is, en as deel van die Park geproklameer (13) is. Hierdie toevoeging het die Park se grootte op 3,272 morg te staan gebring.

Die huidige Park is dus vandag nagenoeg 4 keer groter as die eerste een en die bontbok is terug op sy tuisveld. Siektes, veral gebreksiektes en parasietbesmetting is onbekend. Hulle wei saam met buffeis, rooihartbeeste, elande, springbokke, vaalribbokke, steenbokkies, duikers, grysbokkies en rietbokke oor die hele gebied en omdat weidingsbeheer hier een van die belangrikste take van die Natuurbewaarder is, is daar geen bedreiging dat hulle weer aan gebrekkige voeding sal ly nie.

Die Nasionale Parkeraad het die vitdaging aanvaar om hierdie boksoort van vitsterwing te red en menslikerwyse gesproke reeds daarin geslaag.

\section{ENGLISH SUMMARY:}

The Bontebok's original habitat lan area west of Mosselbay and east of Botriver, wedged in between the Langeberg mountains and the seal was shared by the Hottentot tribes and their stock. After the Colonists started settling there, however, farms were developed and the Bontebok was ousted, to eke out an existence in the sour Strandveld. The first Bontebok National Park was established in 1931 in the Bredasdorp District, and in the beginning they thrived under this protection. Eventually grazing problems, parasite infestation and lack of certain trace elements in the soil, and the progressive 
fall in condition of the animals, forced the Board to look for a new Park in the original habitat. This was found in the Swellendam District, and during 1960 the herd was transferred there.

\section{VERWYSINGS:}

1. Barnard, P. J. en Van der Walt, K.: Translocation of the Bontebok (Damaliscus pygargus) from Bredasdorp to Swellendam. Koedoe, No. 4, 1961. p. 105.

2. Best, G. A., e.a.: Damaliscus dorcas. Rowland Ward's Records of Big Game, 1962 , p. 17.

3. Harper, F.: The nomenclature and type localities of certain Old World Mammals. J. Mam. $21: 191$ and 322, 1940.

4. Harris, W. C.: Portraits of the Game and Wild Animals of Southern Africa (5 parts), London, 1840-1843.

5. Labuschagne, R. J.: Progress Report of the Liaison Officer on the Bontebok National Park. Annexure H 4, Item 31, Agenda for Board Meeting of 8th March, 1957, p. 81.

6. Labuschagne, R. J.: Voorgestelde Terrein vir Nasionale Bontbokpark. Aanhangsel I, Item 12, Agenda vir Raadsvergadering, 10 Desember 1957, bls. 104.

7. Le Vaillant, M.: Travels from the Cape of Good Hope, Vol. 1, 1790, p. 124.

8. Masson, F.: An account of Three Journies from Cape Town into the Southern Parts of Africa. Phil. Trans., 1776, part 1, p. 287.

9. Meester, J., e.a.: An Interim Classification of Southern African Mammals Art. 8, 1964.

10. Roberts, A.: The Mammals of South Africa, 1951, p. 285.

11. Rothmann, M. E. en A.: Die Drostdy op Swellendam (Brosjure).

12. Sclater, W. L.: Mammals of South Africa, Vol. 1, p. 137, 1900.

13. Staatskoerant Nr. 1297 van 10 Desember 1965, Kennisgewing Nr. 317, 1965.

14. Thomlinson, L. L.: Geskiedkundige Swellendam, 1943. 